\title{
High-resolution single nucleotide polymorphism arrays identified an atypical microdeletion of the Williams-Beuren syndrome interval in a patient presenting with a different phenotype
}

\author{
SHIJUN HU ${ }^{1}$, YIFENG YANG $^{1}$, LIN LIU $^{2}$, ZHIPING TAN $^{1}$ and TIANLI ZHAO ${ }^{1}$ \\ Departments of ${ }^{1}$ Cardiovascular Surgery and ${ }^{2}$ Stomatology, \\ The Second Xiangya Hospital, Central South University, Changsha, Hunan 410011, P.R. China
}

Received November 15, 2015; Accepted November 24, 2016

DOI: $10.3892 / \mathrm{mmr} .2017 .6279$

\begin{abstract}
The present study aimed to identify the mutation causing an atypical syndrome. High-resolution single nucleotide polymorphism (SNP) arrays are considered to be a major detection method for submicroscopic chromosomal rearrangements smaller than $5 \mathrm{Mb}$ in size. Genomic DNA samples of the patient and his parents were converted to a final concentration of $50 \mathrm{ng} / \mathrm{ml}$. The Illumina BeadScan genotyping system and the HumanOmni1-Quad Chip were employed to obtain the signal intensities of SNP probes. The patient presented with congenital heart disease, autism, mental retardation, growth retardation, hypercalcemia, nephroliths and cleft palate. The karyotypes of the patient and his parents were normal. The present study employed high-resolution SNP arrays to analyze the whole genome for copy number variations (CNVs). A total of $309 \mathrm{CNVs}$ were discovered. A de novo $1.5 \mathrm{Mb}$ gain of chromosome 7q11.23 (Chr7: 72,357,322-73,856,472) was identified following exclusion of CNVs presented in the Database of Genomic Variants. In conclusion, to the best of our knowledge, the current study describes the first case of a patient presenting with Williams-Beuren syndrome alongside supravalvular aortic stenosis, autism and cleft palate, and identifies an atypical deletion at 7q11.23.
\end{abstract}

\section{Introduction}

Williams-Beuren syndrome (WBS; also termed Williams' syndrome; Online Mendelian Inheritance in Man no. 194050) is characterized by personality, behavioral and emotional wellbeing irregularities, a distinctive facial appearance and

Correspondence to: Dr Tianli Zhao, Department of Cardiovascular Surgery, The Second Xiangya Hospital, Central South University, 139 Renmin Central Road, Changsha, Hunan 410011, P.R. China E-mail:drzhaotl@gmail.com

Key words: high-resolution single nucleotide polymorphism arrays, Williams-Beuren syndrome, autism, cleft palate congenital cardiovascular abnormalities, particularly supravalvular aortic stenosis (SAS). Following its first description in the 1960s $(1,2)$, numerous publications have reported patients with WBS (3-5) and its estimated occurrence was $\sim 1$ in 10,000 (6). Deletion of the WBS chromosome region (WBSCR) on the long arm of chromosome 7, spanning 1.5-1.8 million base pairs and containing 26-28 genes, was defined as the cause of WBS $(7,8)$. However, autism and cleft palate are not part of the major phenotypes associated with WBS. High-resolution single nucleotide polymorphism (SNP) arrays are considered to be an important method for detection of submicroscopic chromosome rearrangements; rearrangements that are $<5 \mathrm{Mb}$ in size (9). The present study provides a detailed report of a patient carrying a de novo $1.5 \mathrm{Mb}$ deletion on chromosome 7q11.23, who presented with congenital heart disease (CHD), autism, mental retardation, growth retardation, hypercalcemia, nephroliths and cleft palate.

\section{Materials and methods}

Clinical description. The current study was approved by the Review Board of the Second Xiangya Hospital of Central South University (Changsha, China). Written informed consent for the publication of the patient images and all other details was obtained from the parents of the patient. The proband, a 5 year old male patient from Hunan province (China), was born at full-term with a length of $45 \mathrm{~cm}$ and a birth weight of 2,650 g. He was one of two children of non-consanguineous parents. At the birth of the patient, the father was 24 years old and the mother was 22 years old. There was no family history of birth defects and his brother was normal in a pedigree analysis. The patient exhibited feeding difficulties, cleft palate and a heart murmur following birth. Subsequently, CHDs, SAS and patent ductus arteriosus (PDA), were identified by transthoracic echocardiography (Fig. 1). At the age of three years, The Department of Cardiovascular Surgery (The Second Xiangya Hospital) suggested that his cardiac defects required treatment for the mild symptoms (PDA, $2 \mathrm{~mm}$; peak SAS gradients, $30 \mathrm{mmHg}$ ). At that time, the patient had moderate growth retardation, weighed $11 \mathrm{~kg}$ and had a height of $85 \mathrm{~cm}$. The patient was later also diagnosed with hypercalcemia, nephroliths and impaired visuospatial abilities 
$\mathbf{A}$

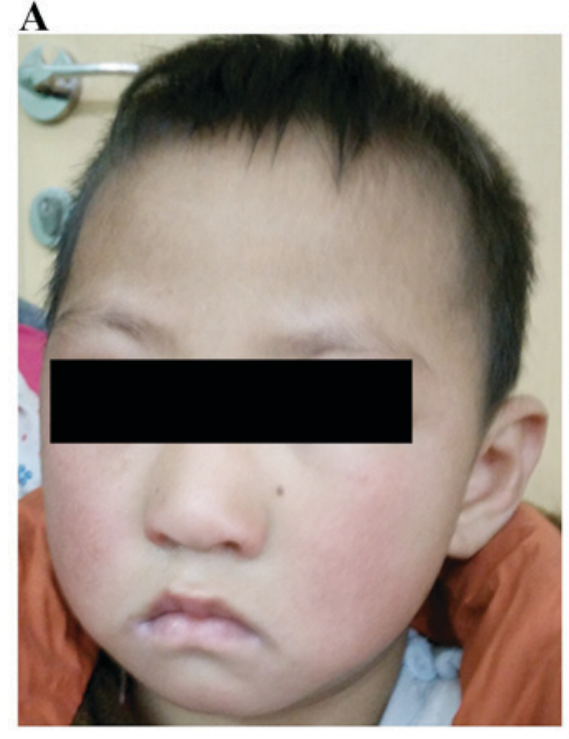

B

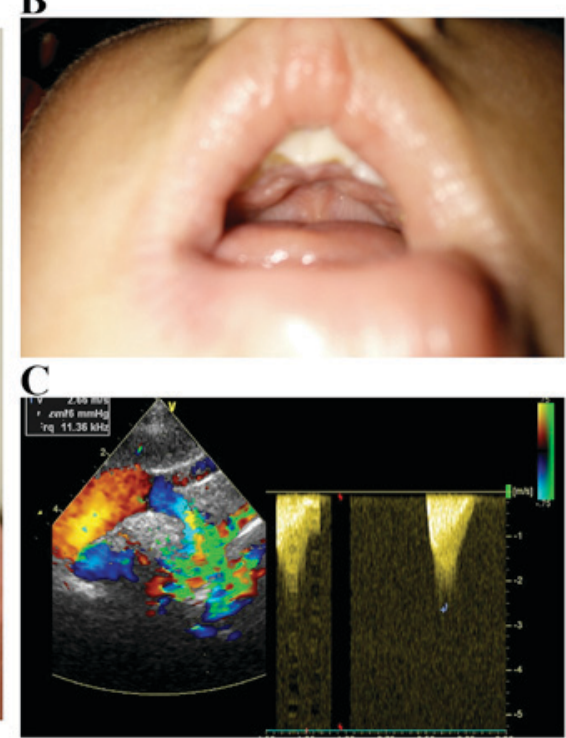

Figure 1. Phenotype of the affected individual. (A) Facial phenotype, (B) sewed cleft palate and (C) echocardiography of supravalvular aortic stenosis. The echocardiogram revealed that the blood flow was accelerated as directed, the acceleration-velocity was $2.66 \mathrm{~m} / \mathrm{sec}$ and the differential pressure was converted as $28 \mathrm{mmHg}$.

following examination. The patient was further diagnosed with autism and severe expressive language impairment by the Mental Health Institute of The Second Xiangya Hospital. The current study used the Autism Diagnostic Interview-Revised (ADI-R) $(10,11)$ to perform diagnostic and behavioral assessments. The patient met the ADI-R criteria for autism in all three domains. The symptoms of the patient included severe deficits in the comprehension of simple language, reciprocal conversation, articulation and socializing with peers. The patient also met the Autism Diagnostic Observation Schedule criteria $(10,12)$ for autism in the restricted behavior, social and communication domain. The patient also presented with excessive non-social anxiety and was easily angered. The cognitive profile of the patient on the Wechsler Preschool and Primary Scale of Intelligence-3rd edition $(13,14)$ highlighted a low IQ range compared with his peers.

Cytogenetic analysis. Peripheral blood $(5 \mathrm{ml})$ from the patient and parents were collected and chromosome analysis by conventional G-banded techniques (550 bands resolution) was performed as previously described $(15,16)$. According to standard cytogenetic protocol (16), all samples were subjected to lymphocyte culture.

DNA extraction. The genomic DNA was extracted from peripheral blood of the patient and his parents. Genomic DNA was prepared using a DNeasy Blood \& Tissue kit (Qiagen, Inc., Valencia, CA, USA) on the QIA cube automated DNA extraction robot (Qiagen, GmbH, Hilden, Germany).

SNP-array analysis. Genomic DNA samples, at a final concentration of $50 \mathrm{ng} / \mathrm{ml}$, of the patient and his parents were used in the present study. The Illumina BeadScan genotyping system (Beadstation Scanner 500; Illumina, Inc., San Diego, CA, USA) and the HumanOmni1-Quad Chip (Illumina, Inc.) were employed to obtain signal intensities of SNP probes.

\section{Results}

The karyotypes of the patient and his parents were normal. The current study employed a high-resolution SNP array system to analyze the whole genome for copy number variations (CNVs). A total of 309 CNVs were discovered. A de novo $1.5 \mathrm{Mb}$ deletion of chromosome 7q11.23 (Chr7: 72,357,322-73,856,472) was identified following the exclusion of CNVs presented in the Database of Genomic Variants $(17,18)$. This chromosome region contains $\sim 17$ notable genes, including elastin (ELN) and the general transcription factor IIi (GTF2I) family (Fig. 2). The parents did not carry this deletion. The $1.1 \mathrm{Mb}$ region that overlapped with the WBSCR interval is indicated in Fig. 2. This region contains certain genes typically associated with Williams-Beuren syndrome, including ELN, GTF2I and bromodomain adjacent to zinc finger domain 1B (BAZ1B).

\section{Discussion}

The patient in the current study presented with atypical phenotypes of CHD, autism, hypercalcemia and cleft palate, which are not usually linked to a diagnosis of WBS. However, high-resolution SNP arrays have proved an effective method of diagnosing syndromes when atypical phenotypes were observed. The deleted region of chromosome 7q11.23 in the patient, reported in the current study, spans $1.5 \mathrm{Mb}$ and includes the genes ELN and the GTF2I family, amongst others. To the best of our knowledge, this is the first patient with WBS to also present with autism and cleft palate reported to date. Most notably, the patient presented with mild SAS and various other phenotypes, including autism and cleft palate, due to the different deleted region compared with the typically reported WBSCR.

Numerous previous publications have reported the co-existence of WBS and autistic disorders with impairments in socialization and communication. Reiss et al (19) initially identified two patients that presented with autism alongside 

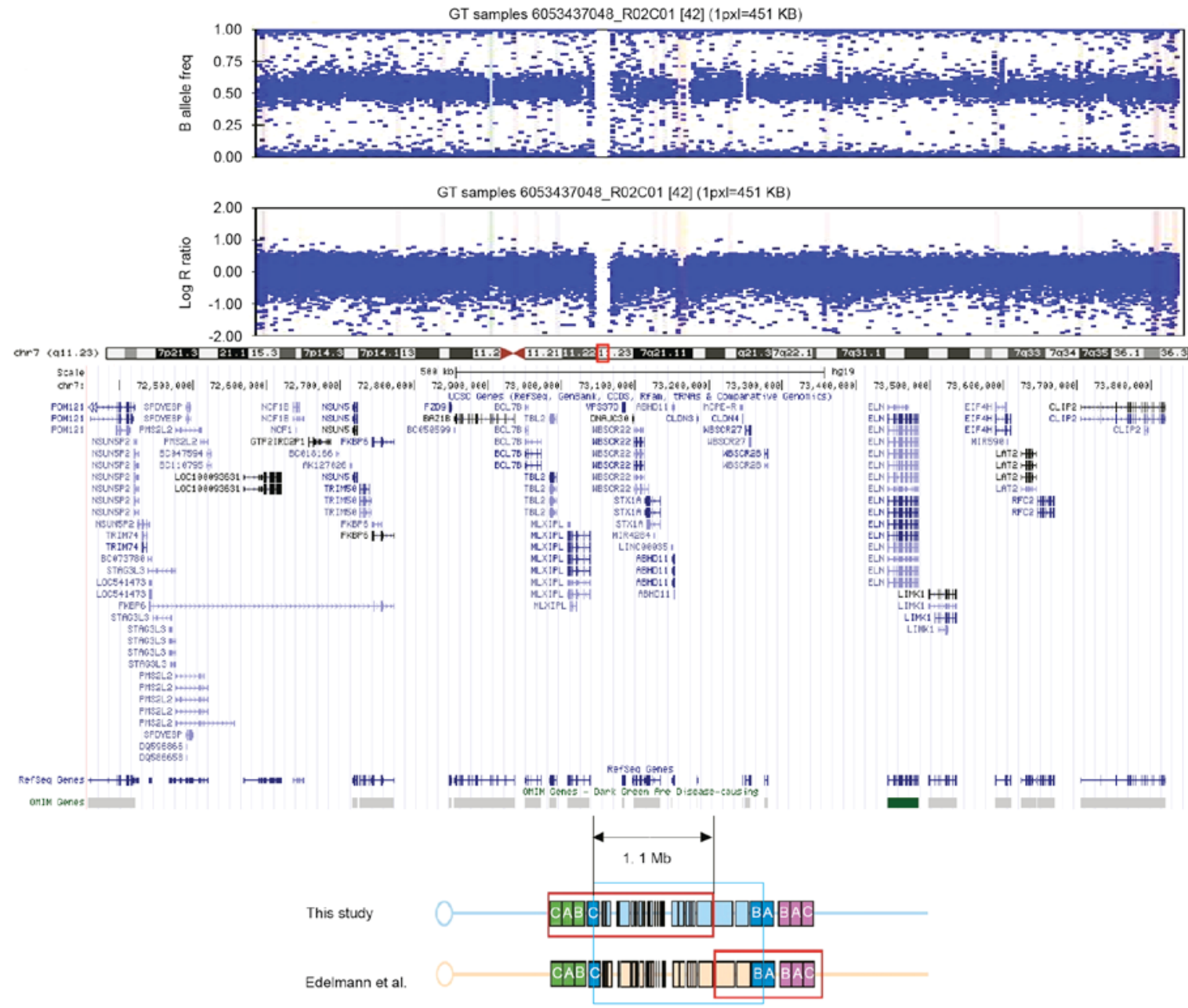

Figure 2. HumanOmni1-Quad Chip results of 7q11.23 deletion in the proband. The top panel presents the region involved in cytogenetic bands 7q11.23. A de novo $1.5-\mathrm{Mb}$ deletion on chromosome $7 \mathrm{q} 11.23$ (Chr7: 72,357,322-73,856,472) was identified. The middle panel presents the key annotated genes. The bottom panel presents the region difference of the present study with that of Edelmann et al (24). The blue box indicates the typical deleted interval of Williams-Beuren syndrome and the red box indicates the deleted interval of affected individuals in the present study and Edelmann et al (24). Chr, chromosome; freq, frequency; GT, genetic test; OMIM, online mendelian inheritance in man.

WBS in 1985. Later, Gillberg and Rasmussen (20) $(\mathrm{n}=4)$, Gosch and Pankau (21) (n=2), Herguner and Mukaddes (22) $(\mathrm{n}=1)$, Leyfer et al (23) (n=9), Edelmann et al (24) $(\mathrm{n}=1)$, Lincoln et al (25) $(\mathrm{n}=1)$, Klein-Tasman et al $(26)(\mathrm{n}=3)$ and Tordjman et al $(27,28)(\mathrm{n}=9)$ reported the dual presence of both disorders. Most patients were diagnosed by clinical manifestation or fluorescence in situ hybridization, only Edelmann et al (24) identified the exact deletion in the chromosome by array-based comparative genomic hybridisation (Fig. 2). Sanders et al (29) reported an association between autism and de novo duplications of 7q11.23, (where the reciprocal deletion causes WBS) characterized by a highly social personality. The patient in the current study presented with certain typical phenotypic characteristics of WBS, including SAS, hypercalcemia, and growth and intelligence retardation. It has been previously suggested that deletion of ELN contributes to SAS (30), and the BAZ1B gene was suggested to contribute to hypercalcemia (31). The GTF2I family, including GTF2I repeat domain containing 1, was suggested to contribute to the specific cognitive deficit exhibited in affected individuals (32-34). However, autism and fear of strangers were not considered to be phenotypes of WBS. Sanders et al (29) reported that duplications of the 7q11.23 WBSCR are strongly associated with autism. As increasing number of patients with WBS are also presenting with autism, and the results of the current study indicate that autistic disorder should be considered as part of the phenotype of WBS. Cleft palate is one of most common congenital craniofacial deformities, but is rarely reported in WBS. Only five cases were reported in a previously published article (35-38), two of them were monozygotic twins and the others were sporadic cases.

In conclusion, to the best of our knowledge, the present study is the first to describe a case of WBS where SAS, autism and cleft palate are also present, and an atypical deletion of 7q11.23 was identified. High-resolution SNP arrays were demonstrated to be an effective method for providing a specific diagnosis of WBS despite the presence of atypical phenotypes.

\section{Acknowledgements}

This study was supported by Hunan Provincial Natural Science Foundation of China (grant no. 2015JJ4085) and the Scientific Research Foundation for the Returned Overseas Chinese Scholars, State Education Ministry (2014; grant no. 1685). 


\section{References}

1. Williams JC, Barratt-Boyes BG and Lowe JB: Supravalvular aortic stenosis. Circulation 24: 1311-1318, 1961.

2. Beuren AJ, Apitz J and Harmjanz D: Supravalvular aortic stenosis in association with mental retardation and a certain facial appearance. Circulation 26: 1235-1240, 1962.

3. Wuang YP and Tsai HY: Sensorimotor and visual perceptual functioning in school-aged children with Williams syndrome. J Intellect Disabil Res: Nov 30, 2016 (Epub ahead of print).

4. Sammour ZM, de Bessa J Jr, Hisano M, Bruschini H, Kim CA, Srougi $\mathrm{M}$ and Gomes CM: Lower urinary tract symptoms in children and adolescents with Williams-Beuren syndrome. J Pediatr Urol: Nov 2, 2016 (Epub ahead of print).

5. Hirai M, Muramatsu Y, Mizuno S, Kurahashi N, Kurahashi H and Nakamura M: Typical visual search performance and atypical gaze behaviors in response to faces in Williams syndrome. J Neurodev Disord 8: 38, 2016.

6. Strømme P, Bjørnstad PG and Ramstad K: Prevalence estimation of Williams syndrome. J Child Neurol 17: 269-271, 2002.

7. Abbas E, Cox DM, Smith T and Butler MG: The 7q11.23 microduplication syndrome: A clinical report with review of literature. J Pediatr Genet 5: 129-140, 2016.

8. Barak B and Feng G: Neurobiology of social behavior abnormalities in autism and Williams syndrome. Nat Neurosci 19: 647-655, 2016.

9. Pinto D, Darvishi K, Shi X, Rajan D, Rigler D, Fitzgerald T, Lionel AC, Thiruvahindrapuram B, Macdonald JR, Mills R, et al: Comprehensive assessment of array-based platforms and calling algorithms for detection of copy number variants. Nat Biotechnol 29: 512-520, 2011.

10. Falkmer T, Anderson K, Falkmer M and Horlin C: Diagnostic procedures in autism spectrum disorders: A systematic literature review. Eur Child Adolesc Psychiatry 22: 329-340, 2013.

11. de Bildt A, Sytema S, Zander E, Bölte S, Sturm H, Yirmiya N, Yaari M, Charman T, Salomone E, LeCouteur A, et al: Autism diagnostic interview-revised (adi-r) algorithms for toddlers and young preschoolers: Application in a non-us sample of 1,104 children. J Autism Dev Disord 45: 2076-2091, 2015.

12. Zander E, Willfors C, Berggren S, Choque-Olsson N, Coco C, Elmund A, Moretti ÅH, Holm A, Jifält I, Kosieradzki R, et al: The objectivity of the autism diagnostic observation schedule (ADOS) in naturalistic clinical settings. Eur Child Adolesc Psychiatry 25: 769-780, 2016.

13. Yu TY, Chen KL, Chou W, Yang SH, Kung SC, Lee YC and Tung LC: Intelligence quotient discrepancy indicates levels of motor competence in preschool children at risk for developmental delays. Neuropsychiatr Dis Treat 12: 501-510, 2016.

14. Trumpff C, De Schepper J, Vanderfaeillie J, Vercruysse N, Van Oyen H, Moreno-Reyes R, Tafforeau J, Vanderpas J and Vandevijvere S: Thyroid-stimulating hormone (TSH) concentration at birth in belgian neonates and cognitive development at preschool age. Nutrients 7: 9018-9032, 2015.

15. Goud TM, Al Salmani KK, Al Harasi SM, Al Musalhi M, Wasifuddin SM and Rajab A: Importance of FISH combined with morphology, immunophenotype and cytogenetic analysis of childhood/adult acute lymphoblastic leukemia in Omani patients. Asian Pac J Cancer Prev 16: 7343-7350, 2015.

16. Peterson JF, Aggarwal N, Smith CA, Gollin SM, Surti U, Rajkovic A, Swerdlow SH and Yatsenko SA: Integration of microarray analysis into the clinical diagnosis of hematological malignancies: How much can we improve cytogenetic testing. Oncotarget 6: 18845-18862, 2015.

17. Sun G, Tan Z, Fan L, Wang J, Yang Y and Zhang W: 1q21.1 microduplication in a patient with mental impairment and congenital heart defect. Mol Med Rep 12: 5655-5658, 2015.

18. MacDonald JR, Ziman R, Yuen RK, Feuk L and Scherer SW: The database of genomic variants: A curated collection of structural variation in the human genome. Nucleic Acids Res 42: D986-D992, 2014.

19. Reiss AL, Feinstein C, Rosenbaum KN, Borengasser-Caruso MA and Goldsmith BM: Autism associated with Williams syndrome. J Pediatr 106: 247-249, 1985.
20. Gillberg C and Rasmussen P: Brief report: Four case histories and a literature review of Williams syndrome and autistic behavior. J Autism Dev Disord 24: 381-393, 1994.

21. Gosch A and Pankau R: Personality characteristics and behaviour problems in individuals of different ages with Williams syndrome. Dev Med Child Neurol 39: 527-533, 1997.

22. Herguner S and Mukaddes NM: Autism and Williams syndrome: A case report. World J Biol Psychiatry 7: 186-188, 2006.

23. Leyfer OT, Woodruff-Borden J, Klein-Tasman BP, Fricke JS and Mervis CB: Prevalence of psychiatric disorders in 4 to 16-year-olds with Williams syndrome. Am J Med Genet B Neuropsychiatr Genet 141B: 615-622, 2006.

24. Edelmann L, Prosnitz A, Pardo S, Bhatt J, Cohen N, Lauriat T, Ouchanov L, González PJ, Manghi ER, Bondy P, et al: An atypical deletion of the Williams-Beuren syndrome interval implicates genes associated with defective visuospatial processing and autism. J Med Genet 44: 136-143, 2007.

25. Lincoln AJ, Searcy YM, Jones W and Lord C: Social interaction behaviors discriminate young children with autism and Williams syndrome. J Am Acad Child Adolesc Psychiatry 46: 323-331, 2007.

26. Klein-Tasman BP, Mervis CB, Lord C and Phillips KD: Socio-communicative deficits in young children with Williams syndrome: Performance on the autism diagnostic observation Schedule. Child Neuropsychol 13: 444-467, 2007.

27. Tordjman S, Anderson GM, Botbol M, Toutain A, Sarda P, Carlier M, Saugier-Veber P, Baumann C, Cohen D, Lagneaux C, et al: Autistic disorder in patients with Williams-Beuren syndrome: A reconsideration of the Williams-Beuren syndrome phenotype. PLoS One 7: e30778, 2012.

28. Tordjman S, Anderson GM, Cohen D, Kermarrec S, Carlier M, Touitou Y, Saugier-Veber P, Lagneaux C, Chevreuil C and Verloes A: Presence of autism, hyperserotonemia, and severe expressive language impairment in Williams-Beuren syndrome. Mol Autism 4: 29, 2013.

29. Sanders SJ, Ercan-Sencicek AG, Hus V, Luo R, Murtha MT, Moreno-De-Luca D, Chu SH, Moreau MP, Gupta AR, Thomson SA, et al: Multiple recurrent de novo CNVs, including duplications of the 7q11.23 Williams syndrome region, are strongly associated with autism. Neuron 70: 863-885, 2011.

30. Curran ME, Atkinson DL, Ewart AK, Morris CA, Leppert MF and Keating MT: The elastin gene is disrupted by a translocation associated with supravalvular aortic stenosis. Cell 73: 159-168, 1993.

31. Pober BR: Williams-Beuren syndrome. N Engl J Med 362: 239-252, 2010.

32. Gagliardi C, Bonaglia MC, Selicorni A, Borgatti R and Giorda R: Unusual cognitive and behavioural profile in a Williams syndrome patient with atypical 7q11.23 deletion. J Med Genet 40: 526-530, 2003.

33. Hirota H, Matsuoka R, Chen XN, Salandanan LS, Lincoln A, Rose FE, Sunahara M, Osawa M, Bellugi U and Korenberg JR: Williams syndrome deficits in visual spatial processing linked to GTF2IRD1 and GTF2I on chromosome 7q11.23. Genet Med 5: 311-321, 2003.

34. Morris CA, Mervis CB, Hobart HH, Gregg RG, Bertrand J, Ensing GJ, Sommer A, Moore CA, Hopkin RJ, Spallone PA, et al: GTF2I hemizygosity implicated in mental retardation in Williams syndrome: Genotype-phenotype analysis of five families with deletions in the Williams syndrome region. Am J Med Genet A 123A: 45-59, 2003.

35. Pankau R, Gosch A, Simeoni E and Wessel A: Williams-Beuren syndrome in monozygotic twins with variable expression. Am J Med Genet 47: 475-477, 1993.

36. Blanco-Dávila F and Olveda-Rodriguez JA: Cleft palate in a patient with Williams' syndrome. J Craniofac Surg 12: 145-147, 2001.

37. Vincent C, Mercier JM and David A: Cleft palate and Williams syndrome. Rev Stomatol Chir Maxillofac 109: 44-47, 2008 (In French).

38. Domenico S, Orlando C, Graziana FF, Papi P and Giulia A: Cleft palate in Williams syndrome. Ann Maxillofac Surg 3: 84-86, 2013. 